\title{
Tradition, Not Science, Is the Basis of Animal Model Selection in Translational and Applied Research
}

\author{
Désirée H. Veening-Griffioen', Guilherme S. Ferreira1, Wouter P. C. Boon², Christine C. Gispen-de Wied ${ }^{3}$, \\ Huub Schellekens ${ }^{1}$, Ellen H. M. Moors ${ }^{2}$ and Peter J. K. van Meer 1,4 \\ ${ }^{1}$ Utrecht Institute of Pharmaceutical Sciences, Utrecht, The Netherlands; ${ }^{2}$ Copernicus Institute of Sustainable Development, Utrecht, The Netherlands; \\ ${ }^{3}$ Gispen4RegulatoryScience: advies en educatie, Bilthoven, The Netherlands; ${ }^{4}$ Medicines Evaluation Board, Utrecht, The Netherlands
}

\begin{abstract}
National and international laws and regulations exist to protect animals used for scientific purposes in translational and applied research, which includes drug development. However, multiple animal models are available for each disease. We evaluated the argumentation behind the selection of a specific animal model using thematic content analysis in project applications issued in 2017-2019 in the Netherlands. In total, 125 animal models for translational and applied research from 110 project applications were assessed. Explanations to select a specific model included: the model's availability $(79 \%)$; the availability of expertise $(62 \%)$; and the model showing similar disease pathology/symptoms $(59 \%)$ to humans. Therefore, current selection of a specific animal model seems to be based on tradition rather than its potential predictive value for clinical outcome. The applicants' explanations for the implementation of the 3R principles (replacement, reduction and refinement) as to the animal model were unspecific. Replacement was achieved by using data from prior in vitro studies, reduction by optimal experimental design and statistics, and refinement by reducing discomfort. Additionally, due to the stated need for a test model with high complexity (47\%) and intactness $(30 \%)$, the full replacement of animal models with alternative (non-live animal) approaches was thought unachievable. Without a clear, systematic and transparent justification for the selection of a specific animal model, the likelihood of poorly translatable research remains. It is not only up to the researcher to demonstrate this, as ethical committees and funding bodies can provide positive stimuli to drive this change.
\end{abstract}

\section{Introduction}

In the (bio)medical field, the development of new drugs is a journey from "bench-to-bedside", in which effective translation of knowledge takes place from basic science into new treatment options for patients. These treatment options may include options to prevent the onset of diseases, or options to (improve) diagnosis, medical devices or treatment with medicinal products, i.e., pharmaceuticals (Woolf, 2008; Fontanarosa and DeAngelis, 2003). However, the translation of knowledge to successful new treatment options, specifically pharmaceuticals, often fails. The failure of drugs in phase II and III clinical trials between 2013-2015 was attributed to lack of safety (24\%), lack of efficacy (52\%) and operational, strategic or commercial reasons (24\%) (Harrison, 2016). Lack of efficacy is partly attributed to non-predictive animal data (Godlee, 2018; Pound et al., 2004; van der Worp et al., 2010). The inability of an animal model to predict clinical outcome has several reasons, which can be summarized as poor exe- cution and poor animal model choice. Poor execution comprises poor design, conduct and reporting of animal studies, leading to false-positive results, as well as inadequate feedback of information observed in clinical trials back to the animal model (Schulz et al., 2016). Poor animal model choice concerns insufficiently taking into account a different etiology in the animal, animal-human species differences, important clinical endpoints not being available or assessed in the animal, as well as the display of different disease and pharmacodynamic markers in the animal (Denayer et al., 2014).

The execution issue can be mended by implementing adequate design and reporting of animal studies for which specific guidelines are available (Percie du Sert et al., 2019; Smith et al., 2018). The animal model choice issue is more difficult to improve as reflected by the following three questions.

First, why are specific animal models chosen to test a specific hypothesis? According to the definition of Held (1980), an animal model of disease is defined as " a living organism in which
Received March 30, 2020; Accepted June 18, 2020; Epub June 22, 2020; @ The Authors, 2020.

ALTEX 38(1), 049-062. doi:10.14573/altex.2003301
This is an Open Access article distributed under the terms of the Creative Commons Attribution 4.0 International license (http://creativecommons.org/licenses/by/4.0/) which permits unrestricted use, distribution and reproduction in any medium, provided the original work is appropriately cited.

Correspondence: Désirée H. Veening-Griffioen, MASc.

Utrecht Institute of Pharmaceutical Sciences, Department of Pharmaceutics

Universiteitsweg 99, 3584 CG Utrecht, The Netherlands

(d.h.veening-griffioen@uu.nl) 


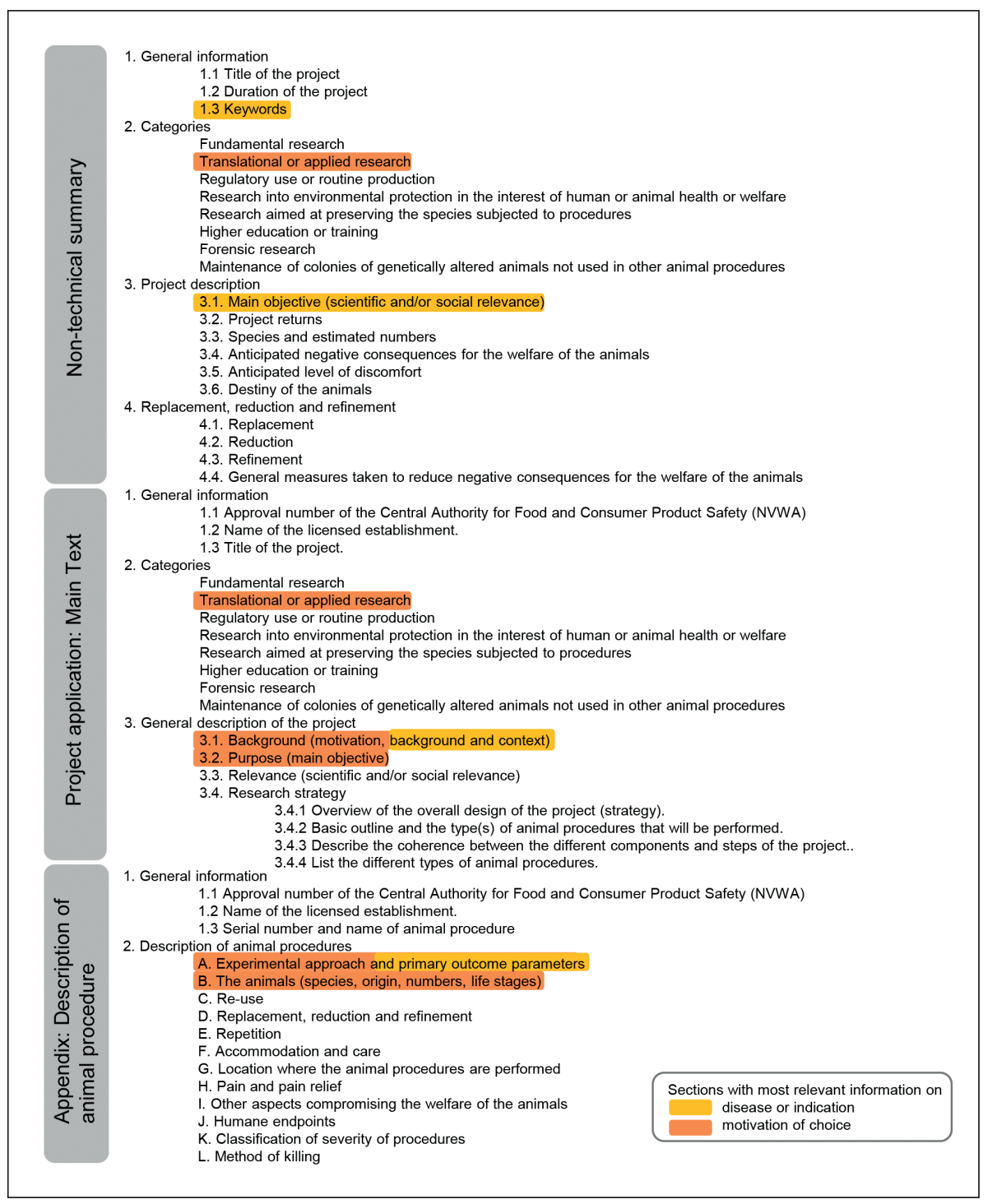

Fig. 1: General outline of the project application form in the Netherlands ${ }^{1}$ Sections with most relevant information on the disease or indication are marked yellow, and sections with most relevant information on the motivation of choice are marked orange. normative biology or behavior can be studied, or in which a spontaneous or induced pathological process can be investigat$e d$, and in which the phenomenon in one or more respects resembles the same phenomenon in humans." For most diseases, many different animal models are available, each showing disease pathology and/or symptoms. In these animal models, the disease pathology or symptoms are generated in one of three main ways: spontaneous, induced (experimental), or via genetic modification. In spontaneous models, the disease pathology or symptoms develop naturally or as a result of a natural mutation. In induced models, the disease pathology or symptoms are induced chemically, biologically or physically in healthy animals. In genetically modified models, the disease pathology or symptoms are a result of genetic modification (Hau, 2008). Even when similar outcome parameters are assessed, the underlying biology in the animal models is often very different. Therefore, a justification of the selected animal model is warranted. However, the justification for animal model selection in peer-reviewed scientific publications is usually broad and general, i.e., a model for the disease, a model sharing some markers of the disease, etc. (Veening-Griffioen et al., 2019). This broad wording is of limited value to assess whether the animal model has the highest potential to predict clinical outcome.

Second, is the animal model that is most appropriate to predict clinical efficacy of the intervention selected? Due to the lack of a standardized method to assess which aspects of the underlying biology of the human disease an animal model can simulate, we recently developed a framework to compare animal models. Assessing animal models with this framework allows a more scientifically-grounded justification for the selection of a specific an-

\footnotetext{
1 https://www.centralecommissiedierproeven.nl/onderwerpen/aanvraag-vergunning/documenten/formulieren/15/5/18/manual-applying-project-licence (accessed 07.01.2020)
} 
imal model (Ferreira et al., 2019). However, due to its novelty, this methodology is yet to be implemented.

Third, how is responsible use of animals for scientific purposes ensured? Societal pressure to do so has been translated into regulation, like the European Union (EU) Directive 2010/63/ EU. Article 13 provides guidance on the choice of methods and species: "The methods selected should use the minimum number of animals that would provide reliable results and require the use of species with the lowest capacity to experience pain, suffering, distress or lasting harm that are optimal for extrapolation into target species." (EU, 2010).

In order to obtain permission to use animals for scientific purposes in the EU, a project application must be submitted to the national central authority for ethical assessment. Regarding this ethical assessment, Directive 2010/63/EU, Article 13 states "Member States shall ensure that a procedure is not carried out if another method or testing strategy for obtaining the result sought, not entailing the use of a live animal, is recognized under the legislation of the Union." (EU, 2010). This means that during the assessment, animal models should be compared with each other, and procedures should be (at least partly) replaced with nonlive animal alternative models, i.e., the implementation of the $3 R$ principles replacement, reduction and refinement.

Due to the availability of many different animal models for the same disease, we were interested in the reason why researchers choose a specific animal model to answer their research question. We hoped to identify specifically which aspects of the animal models are important in the domain of translational and applied research for new treatment options for humans.

We evaluated how the considerations for the use of animals for the purpose of translational or applied research (Directive 2010/63/EU, Article 5), particularly the choice of a specific animal model, are reflected in project applications. We selected project applications in the Netherlands ${ }^{1}$ as illustrative cases within the EU. However, the project application forms ${ }^{1}$ for animal procedures in the Netherlands (Fig. 1) lack a specific question on the justification ("why") of the animal model selection. Nonetheless, the application form provides applicants room to explain their choices, e.g., in the main text in Section 3.4.2 Research strategy: "Provide a basic outline of the different components of the project and the type(s) of animal procedures that will be performed" and in Appendix, Section 2B Description of animal procedures - Animals: "Specify the species, origin, estimated numbers, and life stages. Provide justifications for these choices". The justification of animal model selection is also absent in application forms in other EU Member States, as confirmed by the National Contact Points ${ }^{2}$. Exceptions are the United Kingdom ("Explain your choice of animals, model(s) and method(s)") and Italy ("Justify the animal model adopted"). For other Member States, similar to the Dutch question, a justification for the choice of species is required, i.e., Estonia ("What is the most appropriate animal species for the purpose of the ani- mal experiment"), Greece ("Justify the choice of this species"), Sweden ("Motivate the choice of species"). Outside the EU, the $\mathrm{USA}^{3}$ also asks for justification ("Justify the appropriateness of the species selected").

Recently, the European Commission (EC) published a revised Implementing Decision 2020/569/EU, Annex I, where applicants should specify "With the new knowledge obtained from this project, are the animal models used still the most appropriate? Please specify per species/model, where appropriate." in the non-technical summary (NTS), Section Refinement (EC, 2020).

In the Netherlands, the NTS of each project application is published anonymously online ${ }^{4}$. The corresponding full project applications are proprietary to the individual license holders and therefore not publicly available.

We aimed to get a better understanding of why (justification) applicants selected a specific animal model as a model for a human disease.

\section{Materials and methods}

Project applications for scientific procedures on animals In each EU Member State, the NTS of each project application is published by the national central authority in the local language. The requirements for the NTS are described in Directive 2010/63/EU, Article 43 (EU, 2010). A general outline of the project application form is shown in Figure 1.

The NTS does not contain information on justification for the choice of the animal model. Therefore, we searched on the institutional websites of all license holders in the Netherlands, listed in the Annual report of the National Inspectorate (Nederlandse Voedsel- en Warenautoriteit, 2018), for availability of full-text publications of their institutional project applications.

The data consists of the full text of project applications for animal procedures issued from 2017 to 2019 by the Dutch Central Authority for Scientific Procedures on Animals (CCD) to Utrecht University, University Medical Center Utrecht, Radboud University Nijmegen and Radboud University Medical Center Nijmegen, the Netherlands. Only these four Dutch universities and university hospitals voluntarily publish the full text of their approved project applications for animal procedures on their institutional website for transparency reasons. Project applications were either in English or Dutch. In the documents, some information was undisclosed for reasons of employee privacy or protection of intellectual property as regulated via the Dutch Public Access to Government Information Act ("Wet openbaarheid van bestuur" or "WOB") (Binnenlandse Zaken en Koninkrijksrelaties, 2018), which regulates the disclosure of information by the Dutch government.

We evaluated approved project applications for human unmet medical needs in the domain of translational or applied research. The information listed in Table 1 was extracted from these project applications.

\footnotetext{
2 Member State authorities for Directive 2010/63/EU. National Contact Points as per Article 59 of the Directive. https:/lec.europa.eu/environment/chemicals/lab_animals/ ms_en.htm (accessed 01.02.2020)

3 https://olaw.nih.gov/guidance/obtaining-an-assurance.htm (accessed 01.02.2020)

4 www.centralecommissiedierproeven.nl
} 
Tab. 1: Parameters for data extraction from approved project application forms for translational and applied research

\begin{tabular}{|c|c|c|}
\hline Parameter & Description & Example \\
\hline modellD & $\begin{array}{l}\text { Unique animal model number, consisting of the } \\
\text { application number and a serial number; one application } \\
\text { can encompass up to five different animal models }\end{array}$ & \#20198365_01; mouse model of food allergy \\
\hline licenseID & $\begin{array}{l}\text { Approved project application number as assigned by } \\
\text { the Central Authority (CCD) }\end{array}$ & \#20198365 \\
\hline project_title & $\begin{array}{l}\text { The title of the project application as reported in the } \\
\text { non-technical summary (NTS); in local language (Dutch) }\end{array}$ & $\begin{array}{l}\text { Preventie van voedselallergie door middel van } \\
\text { omega-3 algenolie }\end{array}$ \\
\hline project_domain & $\begin{array}{l}\text { The purpose of the project application (as defined in } \\
\text { Directive 2010/63/EU - Article 5B) }\end{array}$ & Translational or applied research \\
\hline project_target & $\begin{array}{l}\text { Project (primarily) aims to solve an unmet medical need } \\
\text { for humans or non-humans }\end{array}$ & Unmet medical needs for humans \\
\hline model_title & $\begin{array}{l}\text { The title of the animal model as described in } \\
\text { the project application main text Section } 3.4 .4 \text { and } \\
\text { Appendix, Section } 1.3\end{array}$ & $\begin{array}{l}\text { \#20197585_05; Treatment efficacy studies in MPTP } \\
\text { induced PD mouse model }\end{array}$ \\
\hline model_language & Language in which the project application is written & English (ENG) or Dutch (NLD) \\
\hline species & Species used in the animal model & Dog, guinea pig, mouse, pig, etc. \\
\hline spec_loc & $\begin{array}{l}\text { Section in the project application where information on } \\
\text { species is described }\end{array}$ & $\begin{array}{l}\text { NTS, main text or appendix of the approved project } \\
\text { application }\end{array}$ \\
\hline dis_area & $\begin{array}{l}\text { Disease area of the animal model, according to the } \\
\text { human disorders classification in the Directive 2010/63/ } \\
\text { EU Implementing Decision (EC, 2012) }\end{array}$ & $\begin{array}{l}\text { Cancer, infectious disorders, cardiovascular disorders, } \\
\text { nervous and mental disorders, respiratory disorders, } \\
\text { immune disorders, etc. }\end{array}$ \\
\hline dis_loc & $\begin{array}{l}\text { Section in the project application where information on } \\
\text { disease area is described }\end{array}$ & $\begin{array}{l}\text { NTS, main text or appendix of the approved project } \\
\text { application }\end{array}$ \\
\hline model_class & $\begin{array}{l}\text { Animal model class; how the (disease) symptoms } \\
\text { are obtained in the animal model, according to Hau's } \\
\text { classification (Hau, 2008) }\end{array}$ & $\begin{array}{l}\text { Spontaneous, (experimentally) induced, genetically } \\
\text { modified, naïve or healthy (non-induced) }\end{array}$ \\
\hline class_loc & $\begin{array}{l}\text { Section in the project application where information on } \\
\text { animal model class is described }\end{array}$ & $\begin{array}{l}\text { NTS, main text or appendix of the approved project } \\
\text { application }\end{array}$ \\
\hline intervention_type & Type of intervention to be used in the animal model & $\begin{array}{l}\text { Small molecule, biological, gene or cell therapy, herbal } \\
\text { product, vaccine, medical device or diagnostic tool }\end{array}$ \\
\hline intervention_name & Description of the intervention & Wound cover, antibody, drug, etc. \\
\hline intervention_loc & $\begin{array}{l}\text { Section in the project application where information on } \\
\text { the intervention is described }\end{array}$ & $\begin{array}{l}\text { NTS, main text or appendix of the approved project } \\
\text { application }\end{array}$ \\
\hline model_choice & Explanation for the choice of animal model & $\begin{array}{l}\text { \#20197585_04; availability of the model, prior studies } \\
\text { and similar disease pathology/symptoms }\end{array}$ \\
\hline choice_section & $\begin{array}{l}\text { Section in the project application where information on } \\
\text { choice of a specific animal model is described }\end{array}$ & $\begin{array}{l}\text { NTS, main text or appendix of the approved project } \\
\text { application }\end{array}$ \\
\hline species_choice & $\begin{array}{l}\text { Explanation for the choice of a specific species } \\
\text { (Appendix, Section 2B): "Provide information on species. } \\
\text { Justify your choice with respect to the objectives of this } \\
\text { particular type of animal procedure." }\end{array}$ & $\begin{array}{l}\text { \#20197585_01; PINK1 -/- male rats show a } \\
\text { progressive phenotype on behavioral, pathological and } \\
\text { neurochemical measurements }\end{array}$ \\
\hline spcchc_loc & $\begin{array}{l}\text { Section in the project application where information on } \\
\text { choice of species is described }\end{array}$ & $\begin{array}{l}\text { NTS, main text or appendix of the approved project } \\
\text { application }\end{array}$ \\
\hline outcome_choice & $\begin{array}{l}\text { Explanation for the choice of the primary and secondary } \\
\text { outcomes (Appendix, Section } 2 \mathrm{~A}) \text { : "Describe the primary } \\
\text { and secondary outcome parameters. Justify the choice } \\
\text { with respect to the purpose of the project. For scientific } \\
\text { research, these may include clinical parameters and/or } \\
\text { experimental data." }\end{array}$ & $\begin{array}{l}\text { \#20198365_01: ear thickness following intradermal } \\
\text { challenge with the allergen in the ear as measured for } \\
\text { the allergic reaction (skin response), serum IgE and } \\
\text { mast cell (mMCP-1) levels. }\end{array}$ \\
\hline outcome_loc & $\begin{array}{l}\text { Section in the project application where information on } \\
\text { choice of outcomes is described }\end{array}$ & $\begin{array}{l}\text { NTS, main text or appendix of the approved project } \\
\text { application }\end{array}$ \\
\hline
\end{tabular}




\begin{tabular}{|c|c|c|}
\hline Parameter & Description & Example \\
\hline replace_choice & $\begin{array}{l}\text { Justification for replacement of the animal model } \\
\text { (Appendix, Section 2D): "Describe which other options } \\
\text { have been taken into consideration and explain why } \\
\text { these options were not considered applicable for this } \\
\text { project. Explain why the objectives of this project cannot } \\
\text { be achieved: without the use of animals; ..." }\end{array}$ & $\begin{array}{l}\text { \#20197585_02: It is not possible to obtain the required } \\
\text { pharmacokinetic information solely on the basis of in vitro } \\
\text { or in silico studies }\end{array}$ \\
\hline replace_loc & $\begin{array}{l}\text { Section in the project application where information on } \\
\text { replacement is described }\end{array}$ & Appendix of the approved project application \\
\hline reduce_choice & $\begin{array}{l}\text { Justification for reduction of the number of animals } \\
\text { (Appendix, Section 2D): "Describe which other options } \\
\text { have been taken into consideration and explain why } \\
\text { these options were not considered applicable for this } \\
\text { project. Explain why the objectives of this project cannot } \\
\text { be achieved: ... ; using another experimental design } \\
\text { that requires less animals; ..." }\end{array}$ & $\begin{array}{l}\text { \#20197585_02: We are using the absolute } \\
\text { minimum number of animals necessary, still enabling } \\
\text { reliable results. }\end{array}$ \\
\hline reduce_loc & $\begin{array}{l}\text { Section in the project application where information on } \\
\text { reduction is described }\end{array}$ & Appendix of the approved project application \\
\hline refine_choice & $\begin{array}{l}\text { Justification for refinement of the animal model's } \\
\text { procedures (Appendix, Section 2D): "Describe which } \\
\text { other options have been taken into consideration } \\
\text { and explain why these options were not considered } \\
\text { applicable for this project. Explain why the objectives } \\
\text { of this project cannot be achieved: ...; ising another } \\
\text { experimental design that brings less distress or harm } \\
\text { to the animals." }\end{array}$ & $\begin{array}{l}\text { \#20197585_02; To minimize the animals' discomfort } \\
\text { in the subsequent efficacy studies, we are aiming at } \\
\text { the administration route with the lowest discomfort. }\end{array}$ \\
\hline refine_loc & $\begin{array}{l}\text { Section in the project application where information on } \\
\text { refinement is described }\end{array}$ & Appendix of the approved project application \\
\hline
\end{tabular}

Thematic content analysis of the project application forms

The collection of data for the parameters listed in Table 1 was obtained by qualitative content analysis. In brief, this method collects data in a structured way by extracting the data from the identified sources and grouping these parameters into more general, broader categories (Elo and Kyngas, 2008). Information was coded manually using a code that is a part of a phrase or words representing a category.

We investigated the consistency in argumentation within project applications by comparing the justification of the choice of the animal model to the choice of species or outcome. We used color coding to show the number of project applications using similar argumentation (darker colors indicating a high number of project applications and lighter colors indicating a low number of project applications).

To summarize the data, we used $\mathrm{R}$ version 3.6.1 and $\mathrm{R}$ studio (The R Foundation of Statistical Computing). The scripts are provided in File $\mathrm{S}^{5}$, paragraph 1.

\section{Results}

In total, 110 project applications were available for evaluation; 69 from Utrecht University and University Medical Center Utrecht, 41 from Radboud University and Radboud University Medical
Center Nijmegen. These project applications consisted of 150 animal models for the purpose of translational or applied research. Of these, a total of 125 animal models were used for human clinical purposes. The project applications were written in English $(75 \%)$ or Dutch $(25 \%)$. Raw data are provided in File S2 ${ }^{6}$.

\subsection{Distribution of animal models across disease area and animal model class}

Mouse, rat and guinea pig were the predominant rodent species (61, 33 and 5 animal models, respectively). Pig and sheep were the predominant non-rodent species (12 and 5 animal models, respectively). Mice and rats were used across disease areas, while other species seemed to be used in specific disease areas, such as pigs in diseases of the circulatory system, guinea pigs in diseases of the ear and mastoid process, and sheep in diseases of the musculoskeletal system (Fig. 2). Raw data are provided in Table S15.

Animal models were classified according to the classification proposed by Hau (2008). In $84 \%$ of the animal models, disease phenomena were induced chemically, biologically, physically or by genetic modification, in $2 \%$ the disease phenomena developed spontaneously, while in $14 \%$ of the animal models interventions were tested in healthy animals (Fig. 3). Raw data are provided in File $\mathrm{S} 2{ }^{6}$.

The following intervention types were tested in the animal models we studied: diagnostic tools (24\%), small molecular com-

\footnotetext{
5 doi:10.14573/altex.2003301s1

6 doi:10.14573/altex.2003301s2
} 

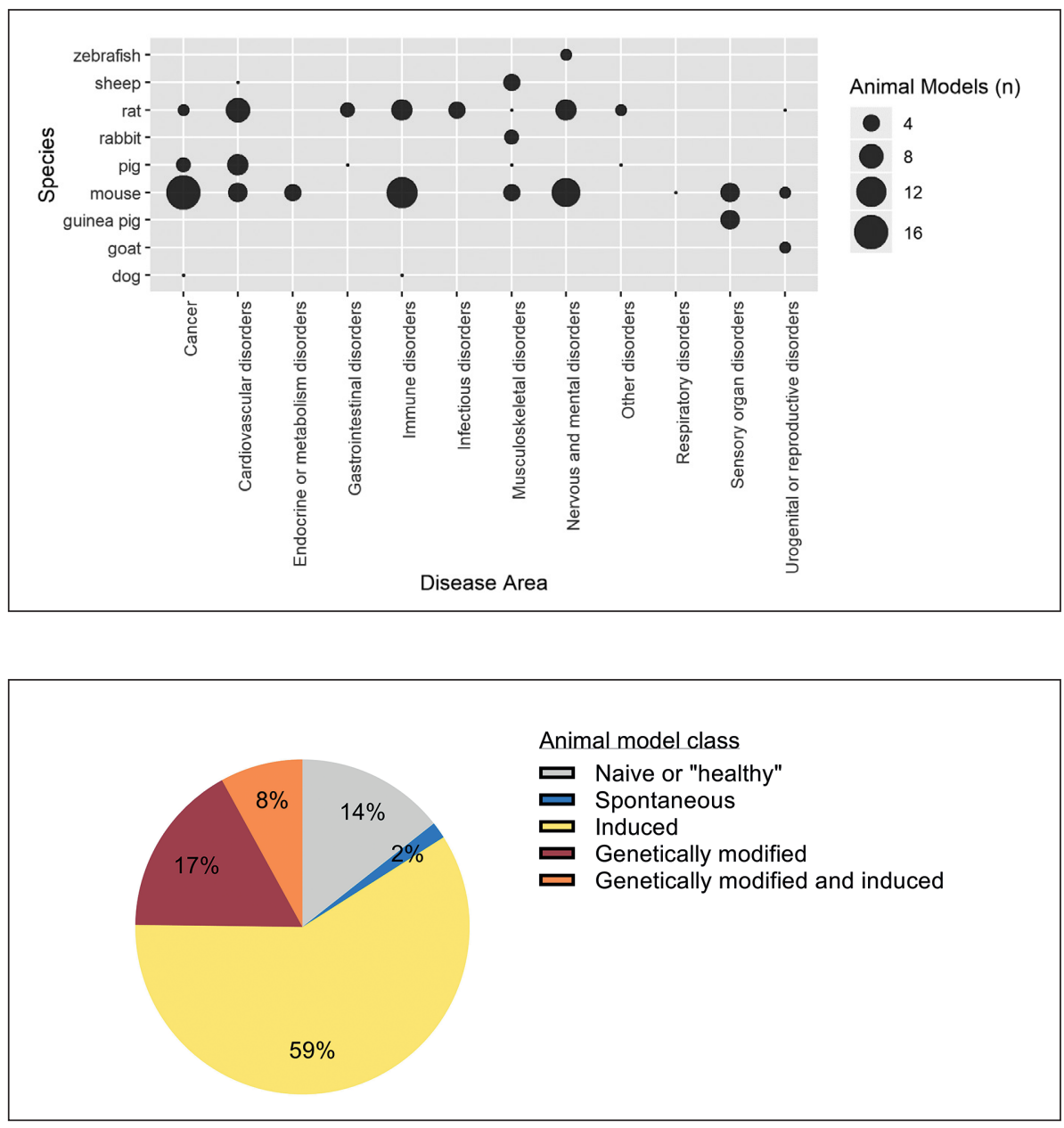

Fig. 2: Distribution of animal models across disease areas and species Disease area classification was according to the human disorders classification in the Directive 2010/63/ EU Implementing Decision (EC, 2012). The bubble size represents the number of animal models with a specific species in a specific disease area.

Fig. 3: Proportion of animal models in different animal model classes Animal model classification, i.e., how the (disease) symptoms are obtained in the animal model, according to the classification proposed by Hau (2008). pounds $(23 \%)$, medical devices $(21 \%)$, biologicals $(19 \%)$, geneand cell-based therapies $(18 \%)$, herbal products $(2 \%)$, and undisclosed (3\%). The intervention type "diagnostic tools" encompassed interventions used to diagnose or detect disease state (e.g., MRI, PET/SPECT, ultrasound, radiolabeled antibody, etc.). The intervention type "medical device" included interventions to facilitate the cure of the disease (e.g., ultrasound to remove plaques, wound-sealant, joint distraction, etc.). Whether the interventions were novel or existing, used to test a theory or compared to other interventions was not assessed.

\subsection{Selection of animal models, species and outcome measures}

The project application form (Fig. 1) does not contain a specific section in which the applicant is asked to justify the choice of a specific animal model. The section of the project application giving the explanation of animal model choice was found across the NTS, main text, the appendixes, or in both main text and appendixes (Fig. 4).

Thematic content analysis of the full text of the project application forms, i.e., the NTS, main text and the appendix describing the animal model, showed that animal models were mainly chosen because of the availability of the model (79\%), i.e., the animal model existed, was used or described earlier; the availability of expertise (62\%); similar disease pathology/symptoms $(59 \%)$ (Fig. 5). Specific examples are presented in Table 2. Raw data are provided in File $\mathrm{S} 2^{6}$.

Within individual project applications, we evaluated the correlation between the choice of a specific animal model (in any section of the project application) in relation to the justification of the choice of a specific species (Appendix, Section 2B of the project application) or outcome (Appendix, Section 2A of the project application). In individual project applications, similar explanations were given for the choice of a specific animal model as well as the choice of species (Fig. 6) or the choice of outcome (Fig. 7). Only one animal model referred to a disease-specific guideline for the choice of outcome measures. Specific examples of applicants' explanations are shown in Table 3 (species) and Table 4 (outcomes). Raw data are provided in Table S2 ${ }^{6}$ (model vs species) and Table S3 ${ }^{5}$ (model vs outcome).

\subsection{Implementation of the 3Rs in project application forms}

Filing a project application for animal procedures does not discharge applicants from the obligation to describe the implementation of the $3 \mathrm{R}$ principles replacement, reduction and refine- 

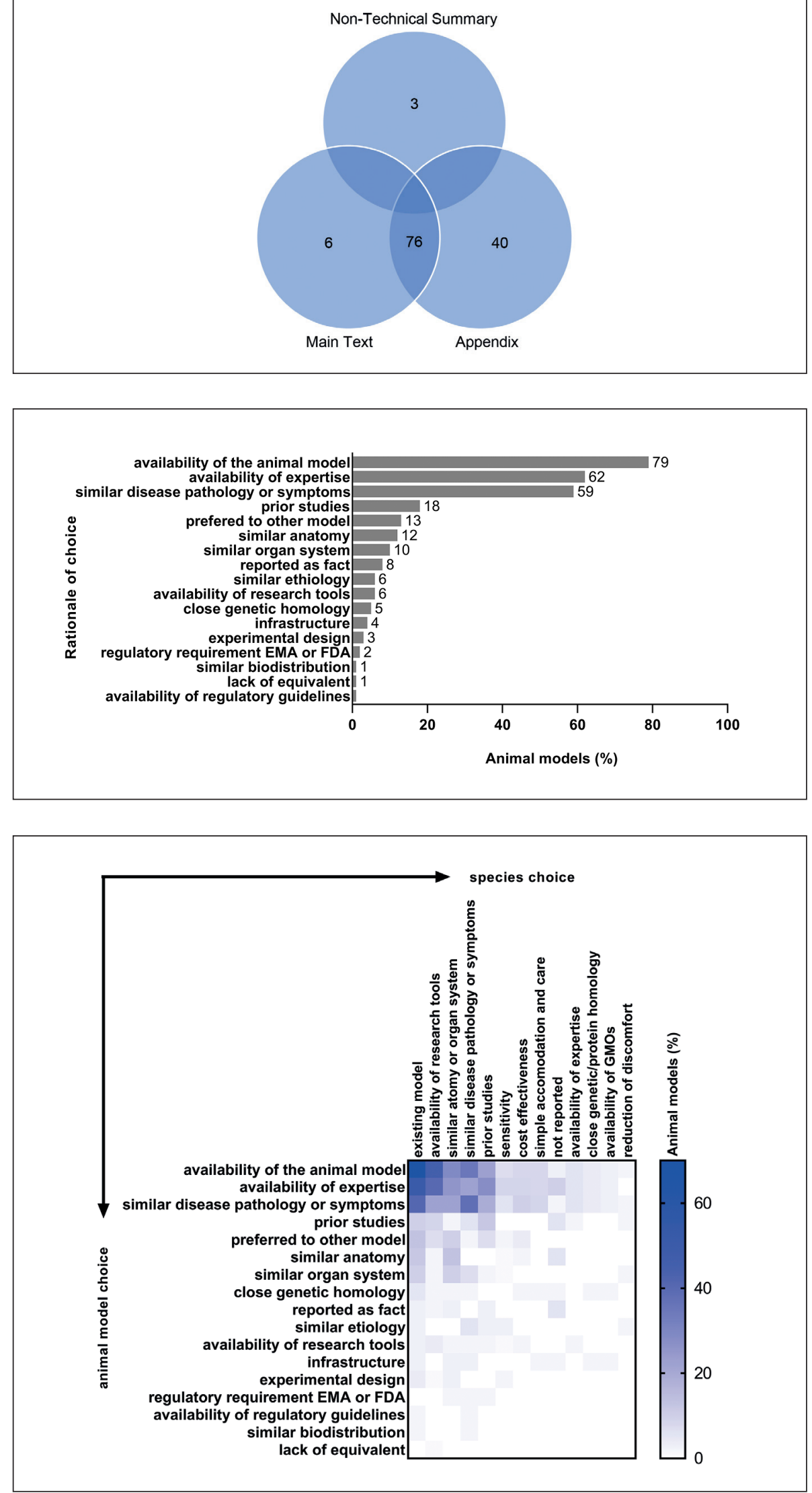

Fig. 4: Justification of animal model choice across different sections of project applications

Different sections of the project application are: the non-technical summary (NTS), main text and the appendix. The number of cases where the explanation for the choice of the animal model was given in a specific section of the project application is given. The numbers in the crosssections indicate justification in more than one section of the same project application.

Fig. 5: Justification for choice of a specific animal model in project applications

Applicant's justification for the choice of a specific animal model, grouped by indicated keywords (y-axis) in \%. Each animal model could be assigned to one or more of the indicated keywords. Specific examples are given in Table 2. Raw data are provided in File $52^{6}$.

Fig. 6: Correlation between animal model choice and species choice in individual project applications

Any information given by the applicant for the choice of a specific animal model (rows) and the choice of a specific species (columns) within the same project application, grouped by indicated keywords. The gradient is the fraction (\%) of animal models with an identified correlation. 


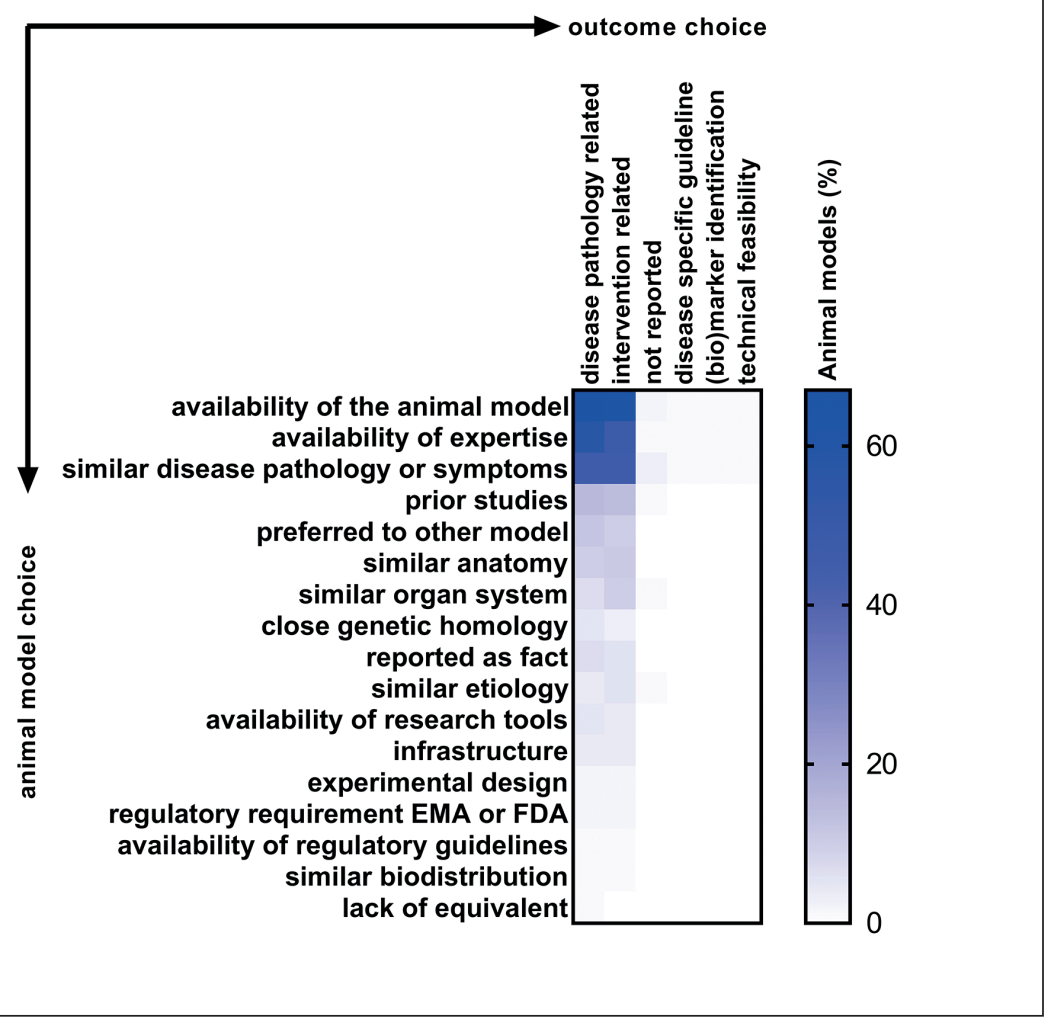

Fig. 7: Correlation between animal model choice and outcome choice in individual project applications Any information given by the applicant for the choice of a specific animal model (rows) and the choice of a specific outcome (columns) within the same project application, grouped per indicated keywords. The gradient is the fraction (\%) of animal models with an identified correlation.

Tab. 2: Justification for the applicants' choice of a specific animal model

Examples of applicants' justifications for the choice of a specific animal model, grouped by the keywords indicated in Figure 5. Where applicable, text from applications in Dutch has been freely translated by the authors.

\begin{tabular}{|c|c|}
\hline Explanation & Example \\
\hline $\begin{array}{l}\text { availability of } \\
\text { the animal model }\end{array}$ & $\begin{array}{l}\text { "The .... procedures we are planning to use have shown to be successful in goats as published by ..."\#20173344_01 } \\
\text { "The mouse was selected because immunodeficient strains are available that allow growth of human tumor } \\
\text { xenografts. Mice are commonly used ...." \#20174286_02 }\end{array}$ \\
\hline $\begin{array}{l}\text { similar disease } \\
\text { pathology or } \\
\text { symptoms }\end{array}$ & $\begin{array}{l}\text { "Full thickness skin defects are used to mimic typical wounds seen in the clinic." \#20171825_01 } \\
\text { "Animal with closest genetic homology to humans... There are various methods to induce .... the most important } \\
\text { aspects to consider are neuropathological and electroencephalographic features that should be replicated in mice } \\
\text { as that seen in human .... patients. Model characterized for its aspects of ... closeness to human ... cell morphology } \\
\text { and animal behavior." \#20184646_02 } \\
\text { "The brains of mice and rats have relatively conserved neuroanatomy compared with human brains, including ... } \\
\text { Involvement of other organs and systems including the enteric system, the olfactory system, and the innate and } \\
\text { adaptive immune systems, can be easily studied in mouse and rat model of PO. They include acute toxin models, } \\
\text { such as ... Some toxin models are well established and have been widely used to test treatment of motor symptoms, } \\
\text { but they do not replicate the progressive nature seen in human PD. Genetic models overcome some drawbacks } \\
\text { of acute models and can recapitulate specific features of PD such as the progressive nature, however it is unlikely that } \\
\text { one model can mimic all features of human PO. Although one model is currently not able to recapitulate PD as seen } \\
\text { in humans, it is important to target and investigate different aspects of this complex neurodegenerative disease by } \\
\text { using multiple models, it allows us to model the PD phenotype better." \#20197585_05 }\end{array}$ \\
\hline $\begin{array}{l}\text { availability of } \\
\text { expertise }\end{array}$ & $\begin{array}{l}\text { "In our department, we performed already extensive research on selected targets and treatments, and we have } \\
\text { over } 30 \text { years of experience with mouse models for .... Furthermore, we have all equipment and tools available to } \\
\text { analyze the therapeutic effects of these ..... therapies in our animal models, and we have fruitful collaborations with...." } \\
\text { \#20173164_02 } \\
\text { "We have an excellent expertise in the field of ... The ... model, descripted in this application is established and } \\
\text { validated. We are well trained in the procedures involved in the study. The study will be performed in collaboration } \\
\text { with a research group in ....., ensuring knowledge transfer." \#20184568_01 }\end{array}$ \\
\hline
\end{tabular}


Tab. 3: Examples of applicants' explanations for the choice of a specific species

Examples of applicants' justifications for the choice of a specific species, as reported in the project application (Appendix Section 2B), grouped by keywords indicated in Figure 6. Where applicable, text from applications in Dutch has been freely translated by the authors.

\begin{tabular}{|l|l|}
\hline Explanation & Example \\
\hline $\begin{array}{l}\text { availability of } \\
\text { the animal model }\end{array}$ & $\begin{array}{l}\text { "The canine species is considered to be a suitable model to study intrinsic cartilage repair." \#20173964_01 } \\
\text { "We will carry out the future tests in the models as we have validated them in the past." \#20198365_01 }\end{array}$ \\
\hline $\begin{array}{l}\text { availability of } \\
\text { research tools }\end{array}$ & $\begin{array}{l}\text { "Standard human diagnostic and interventional devices and imaging equipment can be used. The relative size of } \\
\text { the model allows accurate visualization." \#20173424_01 } \\
\text { "Rat as a model system are chosen since the size and loading capacity of the microspheres limits the needles } \\
\text { size and injection volume. Whereas in a murine knee joint only 6-10ul can be injected, the rat joint enables to inject } \\
60-100 u l \text { with a larger needle." \#20185824_01 }\end{array}$ \\
\hline $\begin{array}{l}\text { similar anatomy } \\
\text { or organ system }\end{array}$ & $\begin{array}{l}\text { "The pig has similar anatomy and (cardio)vascular physiology to humans and is the preferred model for cardiology } \\
\text { procedures." \#20173424_01 } \\
\text { "The sheep model is an excellent animal model for orthopedic research...similar bone composition and bone sizes } \\
\text { as humans." \#20186348_01 }\end{array}$ \\
\hline $\begin{array}{l}\text { similar disease } \\
\text { pathology or } \\
\text { symptoms }\end{array}$ & $\begin{array}{l}\text { "Like humans, dogs suffer for OA and there are well described and validated canine models for OA, including } \\
\text { the Groove model employed for this project. The dog serves as a preclinical model for humans, whit it serves also } \\
\text { the veterinary patient." \#20173964_01 } \\
\text { "Two transgenic DMl mouse models are available: DMSXL, which have symptoms of skeletal muscle and of } \\
\text { the central nervous system. These mice are the only model with clear behavioral defects related to the CNS } \\
\text { involvement. The transgene contains the human DMPK locus with an expanded repeat, which very closely mimics } \\
\text { the situation in DMl patients. HSALR mice, which have a strong phenotype, but exclusively in skeletal muscle. } \\
\text { These mice are best suited for EMG measurements of myotonia. The transgene contains an expanded repeat like } \\
\text { in DMl, but in the context of the human skeletal actin gene instead of the DMPK gene." \#20186204_04 }\end{array}$ \\
\hline
\end{tabular}

Tab. 4: Examples of applicants' explanation for the choice of a specific outcome measure Examples of applicants' justifications for the choice of a specific outcome, as reported in the project application (Appendix Section 2A), grouped by keywords indicated in Figure 7. Where applicable, text from applications in Dutch has been freely translated by the authors.

\begin{tabular}{|c|c|}
\hline Explanation & Example \\
\hline \multirow[t]{3}{*}{$\begin{array}{l}\text { disease pathology } \\
\text { related }\end{array}$} & $\begin{array}{l}\text { "Tail cuff pressure and blood urea will also be measured at multiple time points after scaffold implantation. At } \\
\text { the end-point, under full anesthesia, kidney function will be assessed and intra-arterial catheters will enable us } \\
\text { to measure the drop in pressure over the scaffold while a flow probe will enable u to measure flow through } \\
\text { the scaffold." \#20173344_02 }\end{array}$ \\
\hline & $\begin{array}{l}\text { "Primary outcome parameters will be histology (joint assessment), micro-CT and/or imaging (VHH visualization). } \\
\text { Other outcome parameters may include: blood components (cells, inflammation markers, drug concentration), } \\
\text { synovial fluid components, GAG distribution, RNA expression, AvVFtest and dynamic weight bearing of hind paws } \\
\text { (pressure plate measurements)." \#20185184_01 }\end{array}$ \\
\hline & $\begin{array}{l}\text { "A primary outcome can be based on the mapping of labeled neurons and projections, for example the average } \\
\text { distance from the injection site of all labeled neurons projecting to the brain area of interested. Or morphological } \\
\text { characteristics of dendrites or axonal tracks." \#20197585_04 }\end{array}$ \\
\hline \multirow[t]{2}{*}{$\begin{array}{l}\text { intervention } \\
\text { related }\end{array}$} & $\begin{array}{l}\text { "Detection of cracks, fractures and/or material deformation of the implanted CPC, by in vivo imaging procedures; } \\
\text { analysis of the bone apposition and formation in the region of interest by histomorphometric procedures; } \\
\text { determination of the flexural strength ant toughness of the explanted hemi-mandibles by means of a tensile bench } \\
\text { set-up." \#20173828_01 }\end{array}$ \\
\hline & $\begin{array}{l}\text { "The primary outcome parameter is biodistribution, as measured by fluorescence intensity or other methods such } \\
\text { as hybridization-ligation." \#20186204_02 }\end{array}$ \\
\hline $\begin{array}{l}\text { disease specific } \\
\text { guideline }\end{array}$ & $\begin{array}{l}\text { The combination of these parameters together provides insight into the tissue sensitivity of the plaque, as described } \\
\text { in the guidelines of the American Heart Association (PMID: 7648691). \#20198024_02 }\end{array}$ \\
\hline
\end{tabular}

ment. The applicants justified their choices in unspecific (general) phrasing (Fig. 8). Specific examples are shown in Table 5.

According to the applications, implementation of the $3 \mathrm{Rs}$ was achieved for replacement (Fig. 8A) by referral to prior studies (54\%), mainly prior in vivo, in vitro or ex vivo studies. Reduction (Fig. 8B) was achieved by optimizing the experimental design of the experiments (59\%), largely due to an optimal combination of readouts and substantiated statistics (54\%), mainly through statistical power calculation. Refinement (Fig. 8C) was achieved by reducing the degree of discomfort (85\%) and using the best available methods (42\%). The reduction of discomfort was mainly achieved by providing the best pre- and post-procedure care, and the use of best available methods was achieved due to the applicants' expertise or access to expertise via collaborations. 
A.
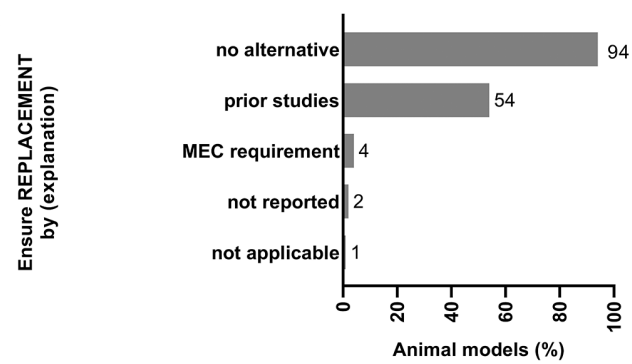

B.

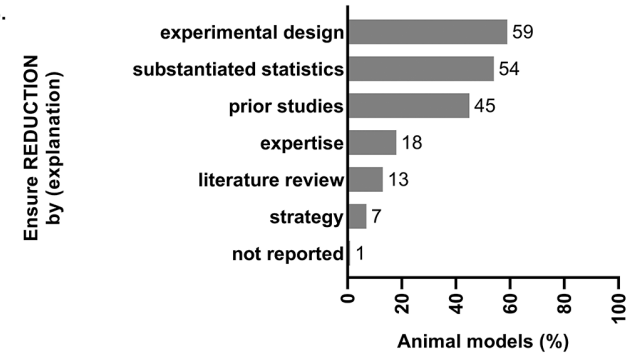

c.
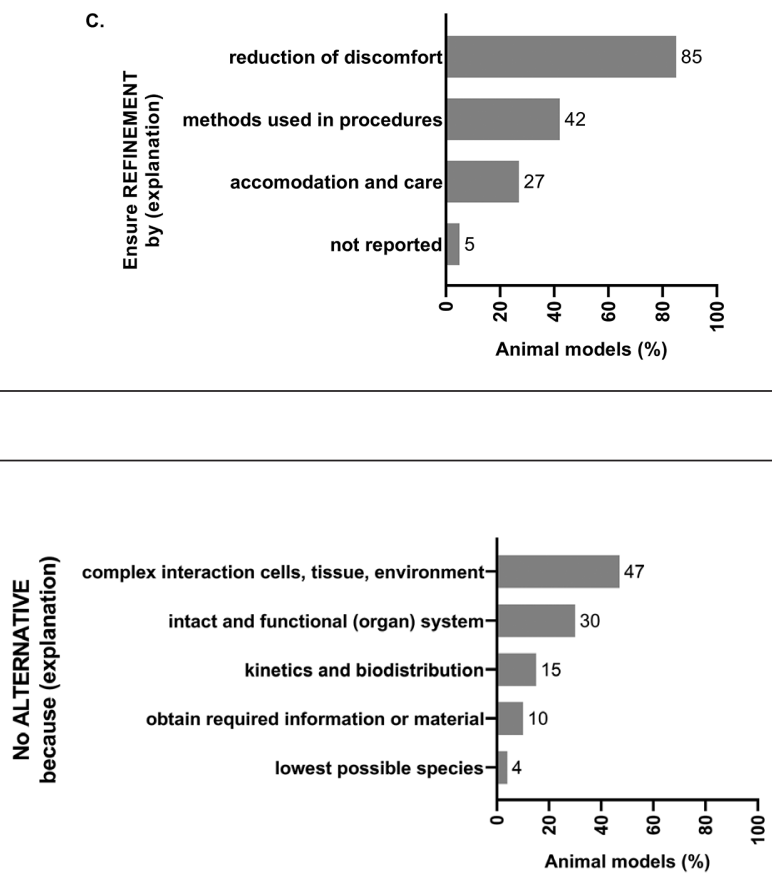

Fig. 8: Foreseen activities to implement replacement, reduction and refinement

Thematic content analysis of any information given by the applicant in Appendix, Section 2D of the project application of other options that had been taken into consideration with regard to replacement $(A)$, reduction (B) and refinement $(C)$ of the animal model, grouped by indicated keywords and reported as fraction (\%) of animal models with a specific explanation. Each animal model could be assigned to one or more of the indicated keywords.
Fig. 9: Justification of the applicants' inability to replace the animal model with a non-live animal alternative model

Applicant's justification, given in Appendix, Section 2D of the project application, of other options which had been taken into consideration with regard to replacement of the animal model, grouped by indicated keywords and reported as fraction (\%) of animal models with a specific explanation.
The main reasons why applicants thought or assessed the full replacement of the animal model with alternative (non-live animal) approaches as insufficient were the requirements of (Fig. 9): the complex interaction between cells, tissue and environment (47\%), an intact and functional (organ) system (30\%), biodistribution $(15 \%)$, or the only way to obtain the information or the only way to obtain the material $(10 \%)$, and the use of the lowest possible species in class (4\%). Raw data are provided in File $S 2^{6}$.

\section{Discussion}

We assessed project applications for animal procedures in the Netherlands. In the domain of translational and applied research, we found that the applicant's justification of animal model selection was based mainly on the availability of the model, the availability of (or access to) expertise and/or the presence of disease-related symptoms (Fig. 5). While the ultimate goal of any project ap- 
Tab. 5: Examples of applicants' explanation for implementation of the 3R principles: replacement, reduction and refinement Applicant's justification for the implementation as reported in the project application (Appendix Section 2D), grouped by indicated keywords of which some examples are given. Numbers are the fraction of animal models with a specific explanation. Where applicable, text from applications in Dutch has been freely translated by the authors.

\begin{tabular}{|c|c|c|}
\hline 3R principle & Explanation & Examples \\
\hline replacement & $\begin{array}{l}\text { no alternative } \\
\text { - complex interaction between environmental factors, } \\
\quad \text { cells or tissues (47\%) } \\
\text { - intact and functional (organ) system (30\%) } \\
\text { - kinetics or biodistribution (15\%) } \\
\text { - obtain required information or material }(10 \%) \\
\text { - lowest possible species (4\%) } \\
\text { prior studies } \\
\text { - in silico, in vitro or ex vivo pre-screening (54\%) } \\
\text { - literature review ( } 2 \%) \\
\text { - in vivo (pilot) studies (1\%) } \\
\text { MEC requirement } \\
\text { - allowing clinical trial }(4 \%) \\
\text { not reported (2\%) } \\
\text { not applicable (1\%) } \\
\text { - obtain required information or material (1\%) }\end{array}$ & $\begin{array}{l}\text { "There are no ex-vivo systems available that can mimic } \\
\text { complex interactions between immune cells, brain } \\
\text { cells and fatigue in a rheumatic disease such as ....." } \\
\text { \#20174167_01 } \\
\text { "Replacement not possible since the entire peripheral } \\
\text { hearing organ must be intact and functional in and } \\
\text { including the connection to the root stem through the } \\
\text { auditory nerve." \#20174315_04 } \\
\text { "Any chelate will first be characterized extensively } \\
\text { in vitro. Only chelates and methods with promising } \\
\text { characteristics will be applied in animals to study their in } \\
\text { vivo characteristics." \#20173885_03 } \\
\text { "And before a new therapy can enter clinical evaluation } \\
\text { pre-clinical in vivo testing is required." \#20174288_01 }\end{array}$ \\
\hline reduction & $\begin{array}{l}\text { experimental design } \\
\text { - optimal combination of readouts (43\%) } \\
\text { - use of one or both sexes ( } 9 \%) \\
\text { - essential treatment groups (6\%) } \\
\text { - method of induction (3\%) } \\
\text { - method of readout (3\%) } \\
\text { substantiated statistics } \\
\text { - statistical power calculation (30\%) } \\
\text { - use of statistical methods (13\%) } \\
\text { - sample size calculation (7\%) } \\
\text { - consult (bio)statistician }(5 \%) \\
\text { prior studies } \\
\text { - in vivo (pilot) studies (28\%) } \\
\text { - in silico, in vitro or ex vivo pre-screening (20\%) } \\
\text { - optimal combination of readouts (1\%) } \\
\text { - relevant information (1\%) } \\
\text { expertise } \\
\text { - experience with model or methodology (16\%) } \\
\text { - expert collaborations (3\%) } \\
\text { literature review } \\
\text { - relevant information ( } 8 \%) \\
\text { - optimal combination of readouts (4\%) } \\
\text { - build on existing literature (1\%) } \\
\text { strategy } \\
\text { - go/no-go strategy (7\%) } \\
\text { not reported (1\%) }\end{array}$ & $\begin{array}{l}\text { "As many readout parameters as possible will be } \\
\text { combined within one animal without increasing the } \\
\text { discomfort. Furthermore, our strategy ...., will guarantee } \\
\text { a careful decision process before continuing with the } \\
\text { next step in the research plan." \#20173164_02 } \\
\text { "Finally, ..., a power calculation will be performed ... if } \\
\text { necessary, experienced pre-clinical researchers and } \\
\text { biostatisticians will be consulted ..." \#20173828_01 } \\
\text { "In addition, only the .... that demonstrate to have the } \\
\text { most favorable in vitro performance ... will be selected for } \\
\text { the animal experiments..." \#20173828_01 } \\
\text { "Our technicians will be trained by experts in the field... } \\
\text { resulting in a steep learning curve...Our laboratory has } \\
\text { a long history of ... in rodents." \#20184985_01 } \\
\text { "Our technicians will be trained by experts in the field... } \\
\text { resulting in a steep learning curve...Our laboratory has } \\
\text { a long history of ... in rodents." \#20184985_01 }\end{array}$ \\
\hline refinement & $\begin{array}{l}\text { reduction of discomfort } \\
\text { - (pre and post) operative care (58\%) } \\
\text { - expertise }(21 \%) \\
\text { - duration of the study }(4 \%) \\
\text { - equipment }(4 \%) \\
\text { - route of administration }(4 \%) \\
\text { - prior (pilot) studies }(2 \%) \\
\text { - terminal anesthesia ( } 2 \%) \\
\text { - best reagents and protocols (1\%) } \\
\text { - experimental design (1\%) } \\
\text { methods used in procedures } \\
\text { - expertise }(28 \%) \\
\text { - best reagents and protocols }(8 \%) \\
\text { - prior (pilot) studies }(6 \%)\end{array}$ & $\begin{array}{l}\text { "During surgical procedures, anesthesia an analgesia is } \\
\text { applied to reduce the discomfort...pain control....softened } \\
\text { food after the operation....state-of-the-art facility... } \\
\text { specialized in housing of ... animals." \#20185825_01 } \\
\text { "We try to minimize discomfort and inefficient use as } \\
\text { much as possible." \#20186348_05 } \\
\text { "Only experienced personnel will carry out ... several } \\
\text { techniques have been initialized and optimized within } \\
\text { our department." \#20184785_01 } \\
\text { "Most of the used in vivo models have already been } \\
\text { optimized and routinely used in the lab... We have } \\
\text { expertise in this field of research...Since literature } \\
\text { showed that this is sufficient to induce ..." \#20186349_01 }\end{array}$ \\
\hline
\end{tabular}




\begin{tabular}{|c|c|c|}
\hline 3R principle & Explanation & Examples \\
\hline & $\begin{array}{l}\text { - experimental design }(6 \%) \\
\text { - lowest possible species }(2 \%) \\
\text { - equipment }(1 \%) \\
\text { accommodation and care } \\
\text { - social housing }(15 \%) \\
\text { - cage enrichment }(14 \%) \\
\text { - expertise }(3 \%) \\
\text { not reported }(5 \%)\end{array}$ & $\begin{array}{l}\text { "Where possible, animals will be housed socially. If } \\
\text { animals were to be housed individually, it would be for a } \\
\text { maximum of } 5 \text { weeks" \#20173846_01 } \\
\text { "To reduce anxiety, mice will be housed in groups and not } \\
\text { individually." \#20173885_05 }\end{array}$ \\
\hline
\end{tabular}

plication is to develop new treatment options for a specific disease, the choice of animal model outcomes (Fig. 7) was not necessarily driven by diagnostic or prognostic outcome markers or regulatory guidelines, as published by EMA or FDA. In this regard, Langhof and colleagues recently published a summary of available clinical guidelines per drug class (Langhof et al., 2018), which could give more focus on relevant outcome markers for pre-clinical research.

Next, filing a project application for animal experiments does not discharge the researcher from implementing the $3 \mathrm{R}$ principles, replacement, reduction and refinement in these animal models. Applicants must demonstrate ${ }^{7}$ that aspects of the $3 \mathrm{R}$ principles have been considered and implemented where possible (Fig. 8) in accordance with Directive 2010/63/EU, Article 13 (EU, 2010). However, the phrasing in the project applications on how this was achieved was overall unspecific and did not meet specific, measurable, achievable or timely (SMART) criteria. Therefore, it was not possible to ascertain that the applicants were compliant with the Directive. For example, applicants proposed to perform a literature search, but none of the applications included information on databases (e.g., PubMed, Web of Science, EMBASE) or a description of the search string used, inclusion or exclusion criteria, etc., nor were the results of these searches reported and discussed. Also, applicants intended only to proceed with their interventions in animal studies, with promising in vitro candidates, as well as the use of experts and best reagents and protocols, but did not include any qualification criteria for these attributes.

Interestingly, the applicants gave explanations for not being able to (fully) replace the animal experiment with a non-live animal alternative model. Explanations were the requirement of the model to comprise complexity or the requirement of an intact system in order to answer the research question (Fig. 9). This suggests that either researchers are not aware of appropriate non-live animal alternative models, or non-live animal alternative models are currently not good enough to be able to fully replace the animal models, or not all animal models are eligible for full replacement at all. When looking at the total number of animal experiments in the Netherlands, we do not see a strong reduction of the total number of animal experiments in the last three years despite the strong governmental endorsement of the development of animal-free innovations (Nederlandse Voedsel- en Warenautoriteit, 2018; ${ }^{8}$ ).

Overall, in all project applications, it remained unclear whether the selected animal model was the model with the highest likelihood of predicting the clinical outcome. A clear justification and scientific discussion on "why" and based on "what" specific animal models or outcomes are chosen was often absent, suggesting the applicants selected their animal model based on a "trust me" (tradition) rather than a "show me" approach. This tradition-driven approach in animal model selection is described by innovation scientist Kooijman (2013) as "locked-in", i.e., the use of animals to predict events in humans is "locked-in" because animal experiments are embedded in a well-aligned set of institutions, such as regulations, norms and values, that are taken for granted and are normatively endorsed. This "lock-in" slows down innovations in this area.

\subsection{Recommendations for applicants}

The reported lack of detailed information and the tradition-driven way of working, i.e., "I am an expert" or "I have used this model before", is not unknown in the field of animal experimentation. Herrmann and Flecknell $(2018,2019)$ also showed this tradition-driven way of working for the regimens used for anesthetics and analgesia, as well as for humane endpoints.

Several steps could be taken to improve the value of animal models in drug development.

First, a clear and scientific justification should be made for the appropriateness of the animal model in relation to other models for the same indication, as well as its expected predictive value for human outcome. A standardized methodology, like the Framework to Identify Models of Disease (FIMD), is a way to facilitate this process (Ferreira et al., 2019). FIMD addresses the following aspects of animal models in a standardized way: What is known of the biology of the human disease, how is this reflected in the animal model, is the disease target similar, and is the target similarly regulated in the animal compared to humans, why are particular parameters measured, how similar and relevant are they for the human disease, what is the effect of known human effective and ineffective interventions, etc.

Second, the quality of animal studies should be improved. This could be achieved by the mandatory use of study design protocols, preregistration tools and correct reporting (Smith et al., 2018; Macleod and Mohan, 2019). The scientific community is increasingly aware of the need for more explicit and transparent reporting of animal research in scientific publications, leading to the publication of reporting standards such as the ARRIVE reporting guidelines (Kilkenny et al., 2010). Unfortunately, although the ARRIVE guidelines are endorsed by many scientific journals, neither the reporting quality of animal studies (Leung et al., 2018) nor the level

\footnotetext{
7 https://www.ncadierproevenbeleid.nl/dierproeven-en-3V-methoden/themas/vervanging-vermindering-en-verfijning (accessed 24.02.2020)

8 https://www.ncadierproevenbeleid.nl/adviezen-ncad/documenten/rapport/2016/12/15/ncad-advies-transitie-naar-proefdiervrij-onderzoek (accessed 24.02.2020)
} 
of reproducibility of animal studies (Freedman et al., 2015) has improved. At least, correct reporting should be checked by journals before publication.

Third, an increase in transparency of animal research for scientific purposes is needed. There is a public perception that animal research is secretive and thus not sufficiently transparent (Pound and Blaug, 2016; Leaman et al., 2014). Although part of the data obtained from animal studies is available via publication of the results from animal studies in scientific journals, most of the data generated by industry is not published. In accordance with Directive 2010/63/EU, the NTS of project applications of all license holders (public and private) must be published online in all EU Member States, which provides some insight into animal research in the EU. The full publication of project applications, as done by Utrecht University, University Medical Center Utrecht, Radboud University Nijmegen and Radboud University Medical Center Nijmegen, is a leading example of higher transparency, "show me" research.

Besides increased transparency, full publication of project applications may also decrease repetition of studies and create a platform for peer-review, which will improve the study results, i.e., their reliability. To facilitate this, the CCD in the Netherlands stated in her annual plan for 2020": "Although the Non-Technical Summary of the issued projects provides insight into the types of research that are taking place in the Netherlands, there is also a call from society for further insight into the projects. The CCD therefore strongly supports and encourages active and full disclosure of projects by the institutes themselves."

\subsection{Limitations of our study}

Our data includes project applications for the use of animal experiments for scientific purposes. These project applications were filed because the applicants were not able to (fully) replace the animal model using a non-live animal alternative model (Fig. 8 ). It is unclear how many applications were not filed because it was possible to fully replace the animal model with a non-live alternative model.

Our data does not reflect the total of translational and applied research in the Netherlands, since only project application forms of 4 out of 80 institutes with an active license to perform animal experiments in the Netherlands were available for assessment. However, personal communication with representatives from different institutional animal welfare bodies and animal ethics committees in the Netherlands, in both industry and academia, suggest similar outcomes across the country.

\subsection{Perspectives for researchers, regulatory bodies and funding agencies}

The change from "trust me" toward "show me" is not achieved only by transparent reporting, i.e., full-text publication of project applications. More specific guidance is needed, including on the expected level of detail on "how" (method) and "what" (deliveries) is expected from the applicant as justification for animal model selection.

We suggest the following improvements to the current project application form: (1) Add the disease area in human beings or an- imals for which prevention, diagnosis or treatment is intended. (2) Add why a specific animal model is chosen over others. (3) Add clinically relevant diagnostic or prognostic markers, and, where available, EMA/FDA/EFSA suggested markers to show efficacy of interventions.

We strongly recommend researchers to scientifically justify their choice of animal model as the best model to predict clinical outcome. Ethics committees and the national central authority of every country should demand specific and standardized arguments. Funding agencies should refrain from funding projects for which it is unclear whether the chosen animal models are the best models to predict clinical outcome.

In summary, in project applications for the use of animals in scientific applications, the current choice of a specific animal model seems to be based on tradition rather than its potential to predict the clinical outcome. A specific and standardized substantiation of the choice of an animal model will lead to more robust science, better prediction of drug efficacy, and more responsible use of animals in drug development.

\section{References}

Binnenlandse Zaken en Koninkrijksrelaties (2018). Wet openbaarheid van bestuur. Staatsblad van het Koninkrijk der Nederlanden 248, BWBR0005252.

Denayer, T., Stöhr, T. and Van Roy, M. (2014). Animal models in translational medicine: Validation and prediction. New Horiz Transl Med 2, 5-11. doi:10.1016/j.nhtm.2014.08.001

Elo, S. and Kyngas, H. (2008). The qualitative content analysis process. $J$ Adv Nurs 62, 107-115. doi:10.1111/j.1365-2648. 2007.04569.x

EC - European Commission (2012). Commission Implementing Decision of 14 November 2012 establishing a common format for the submission of the information pursuant to Directive 2010/63/EU of the European Parliament and of the Council on the protection of animals used for scientific purposes. OJ L 320 , 33-50. http://data.europa.eu/eli/dec_impl/2012/707/oj

EC (2020). Commission Implementing Decision (EU) 2020/569 of 16 April 2020 establishing a common format and information content for the submission of the information to be reported by member states pursuant to Directive 2010/63/EU of the European Parliament and of the Council on the protection of animals used for scientific purposes and repealing Commission Implementing Decision 2012/707/EU (notified under document C(2020) 2179). OJ L 129, 16-50. http://data.europa.eu/eli/dec_impl/2020/569/oj EU - European Union (2010). Directive 2010/63/EU of the European Parliament and of the Council of 22 September 2010 on the protection of animals used for scientific purposes. OJ L 276, 33 79. http://data.europa.eu/eli/dir/2010/63/oj

Ferreira, G. S., Veening-Griffioen, D. H., Boon, W. P. C. et al. (2019). A standardised framework to identify optimal animal models for efficacy assessment in drug development. PLoS One 14, e0218014. Erratum in: PLoS One 14, e0220325. doi:10.1371/ journal.pone.0218014

Fontanarosa, P. B. and DeAngelis, C. D. (2003). Translational med-

\footnotetext{
9 https://www.centralecommissiedierproeven.nl/documenten/vergaderstukken/2020/1/jaarplan/jaarplan2020
} 
ical research. JAMA 289, 2133. doi:10.1001/jama.289.16.2133

Freedman, L. P., Cockburn, I. M. and Simcoe, T. S. (2015). The economics of reproducibility in preclinical research. PLoS Biol 13, e1002165. doi:10.1371/journal.pbio. 1002165

Godlee, F. (2018). We need better animal research, better reported. BMJ 360, k124. doi:10.1136/bmj.k124

Harrison, R. K. (2016). Phase II and phase III failures: 2013-2015. Nat Rev Drug Discov 15, 817-818. doi:10.1038/nrd.2016.184

Hau, J. (2008). Animal models for human diseases. In P. M. Conn (ed.), Sourcebook of Models for Biomedical Research. Totowa, NJ, USA: Humana Press. doi:10.1007/978-1-59745-285-4_1

Held, J. R. (1980). Muhlbock memorial lecture: Considerations in the provision and characterization of animal models. In A. Spiegel, S. Erichsen and H. A. Solleveld (eds.), Animal Quality and Models in Biomedical Research, $7^{\text {th }}$ ICLAS Symposium Utrecht 1979. Stuttgart, Germany: Gustav Fisher Verlag.

Herrmann, K. and Flecknell, P. (2018). The application of humane endpoints and humane killing methods in animal research proposals: A retrospective review. Altern Lab Anim 46, 317-333. doi:10.1177/026119291804600606

Herrmann, K. and Flecknell, P. (2019). Retrospective review of anesthetic and analgesic regimens used in animal research proposals. ALTEX 36, 65-80. doi:10.14573/altex.1804011

Kilkenny, C., Browne, W. J., Cuthill, I. C. et al. (2010). Improving bioscience research reporting: The ARRIVE guidelines for reporting animal research. PLoS Biol 8, e1000412. doi:10.1371/ journal.pbio.1000412

Kooijman, M. (2013). Why animal studies are still being used in drug development. Altern Lab Anim 41, P79-81. doi:10.1177/ 026119291304100627

Langhof, H., Chin, W. W. L., Wieschowski, S. et al. (2018). Preclinical efficacy in therapeutic area guidelines from the U.S. Food and Drug Administration and the European Medicines Agency: A cross-sectional study. Br J Pharmacol 175, 4229-4238. doi: 10.1111/bph. 14485

Leaman, J., Latter, J. and Clemence, M. (2014). Attitudes to animal research in 2014. Ipsos MORI Social Research Institute, London. https:/www.ipsos.com/sites/default/files/migrations/en-uk/files/ Assets/Docs/Polls/sri_BISanimalresearch_NONTRENDreport. pdf (accessed 13.12.2019)

Leung, V., Rousseau-Blass, F., Beauchamp, G. et al. (2018). ARRIVE has not ARRIVEd: Support for the ARRIVE (animal research: Reporting of in vivo experiments) guidelines does not improve the reporting quality of papers in animal welfare, analgesia or anesthesia. PLoS One 13, e0197882. doi:10.1371/journal. pone. 0197882

Macleod, M. and Mohan, S. (2019). Reproducibility and rigor in animal-based research. ILAR J 60, 17-23. doi:10.1093/ilar/ilz015

Nederlandse Voedsel- en Warenautoriteit (2018). Zo doende 2017. Jaaroverzicht dierproeven en proefdieren van de nederlande voedsel- en warenautoriteit. Nederlandse Voedsel- en Warenautoriteit, 1-62.

Percie du Sert, N., Hurst, V., Ahluwalia, A. et al. (2019). The ARRIVE guidelines 2019: Updated guidelines for reporting animal research. PLoS Biol 18, e3000410. doi:10.1371/journal. pbio. 3000410
Pound, P., Ebrahim, S., Sandercock, P. et al. (2004). Where is the evidence that animal research benefits humans? BMJ 328, 514517. doi:10.1136/bmj.328.7438.514

Pound, P. and Blaug, R. (2016). Transparency and public involvement in animal research. Altern Lab Anim 44, 167-173. doi:10.1177/026119291604400210

Schulz, J. B., Cookson, M. R. and Hausmann, L. (2016). The impact of fraudulent and irreproducible data to the translational research crisis - Solutions and implementation. J Neurochem 139, Suppl 2, 253-270. doi:10.1111/jnc. 13844

Smith, A. J., Clutton, R. E., Lilley, E. et al. (2018). Prepare: Guidelines for planning animal research and testing. Lab Anim 52, 135 141. doi:10.1177/0023677217724823

van der Worp, H. B., Howells, D. W., Sena, E. S. et al. (2010). Can animal models of disease reliably inform human studies? PLoS Med 7, e1000245. doi:10.1371/journal.pmed.1000245

Veening-Griffioen, D. H., Ferreira, G. S., van Meer, P. J. K. et al. (2019). Are some animal models more equal than others? A case study on the translational value of animal models of efficacy for Alzheimer's disease. Eur J Pharmacol 859, 172524. doi: 10.1016/j.ejphar.2019.172524

Woolf, S. H. (2008). The meaning of translational research and why it matters. JAMA 299, 211-213. doi:10.1001/jama.2007.26

\section{Conflict of interest}

GSF reports personal fees from Merck KGaA and Curare Consulting B.V. outside of the submitted work. DVG reports personal fees from Nutricia Research B.V. and Merck Sharp \& Dohme outside of the submitted work. None of the other authors has any conflicts of interest.

\section{Author's contributions}

Conception and design (DVG, GF and PvM), acquisition, analysis and interpretation of data (DVG), drafting the article (DVG) and revising it critically for important intellectual content (DVG, GF, WB, HS, EM and PvM) and final approval of the version to be published, agreement to be accountable for all aspects of the work in ensuring that questions related to the accuracy or integrity of any part of the work are appropriately investigated and resolved (all authors).

\section{Funding}

This work was supported by the Dutch Ministry of Agriculture, Nature and Food Quality and the Ministry of Health, Welfare and Sport.

\section{Acknowledgement}

The authors thank the representatives from animal welfare bodies, animal ethical committees, researchers and others who participated in our workshop on this topic. Your contribution was of great value. 